\title{
Forms of vitality play and symbolic play during the third year of life.
}

\section{Español, Silvia, Bordoni, Mariana, Martínez Mauricio y Carretero, Soledad.}

Cita:

Español, Silvia, Bordoni, Mariana, Martínez Mauricio y Carretero, Soledad (2015). Forms of vitality play and symbolic play during the third year of life. INFANT BEHAVIOR \& DEVELOPMENT, 40, 242-252.

Dirección estable: https://www.aacademica.org/silvia.espanol/80 ARK: https://n2t.net/ark:/13683/pH0V/qpb 


\title{
Forms of vitality play and symbolic play during the third year of life
}

\author{
Silvia Español ${ }^{\mathrm{a}, \mathrm{b}, *}$, Mariana Bordoni $^{\mathrm{a}, \mathrm{b}}$, Mauricio Martínez ${ }^{\mathrm{b}, \mathrm{c}}$, \\ Rosario Camarasa ${ }^{\mathrm{d}}$, Soledad Carretero ${ }^{\mathrm{a}, \mathrm{b}}$ \\ a CONICET, Consejo Nacional de Investigaciones Científicas y Técnicas, Argentina \\ b FLACSO, Facultad Latinoamericana de Ciencias Sociales, Argentina \\ c APADEA, Asociación Argentina de Padres de Autistas, Argentina \\ d UAI, Universidad Abierta Interamericana, Argentina
}

\section{A R T I C L E I N F O}

\section{Article history:}

Received 19 December 2014

Received in revised form 14 May 2015

Accepted 22 May 2015

\section{Keywords:}

Play

Symbolic play

Forms of vitality

Forms of vitality play

\begin{abstract}
A B S T R A C T
This article focuses on the development of forms of vitality play, a recently described type of play, and links it to the development of symbolic play, one of the most studied types of play in developmental psychology. Two adult-infant dyads were videotaped longitudinally during in-house free play meetings every 15 days during the third year of life. Convergence technique was applied in order to accelerate the longitudinal study. A total of $17 \mathrm{~h} 48 \mathrm{~min}$ were registered in 28 sessions. An observational code with categories of forms of vitality play (a non-figurative play frame in which child and adult play together with the dynamics of their own movements and sounds in a repetition-variation form), symbolic play, and categories of combined patterns of both types of play was applied. The rate of each play was calculated for different age periods. Forms of vitality play is present at a constant rate during the third year of life. Symbolic play flourishes during this period. Combined play patterns are not the most frequent but are present from the beginning to the end of the third year. We suggest that FoVP favours intimate and intersubjective experiences essential to the understanding and the development of the interpersonal world; that it can be thought of as a good runway for the development of symbolic play; and that it prepares the child to participate in the temporal arts that belong to his culture.
\end{abstract}

(c) 2015 Elsevier Inc. All rights reserved.

\section{Introduction}

\subsection{Introducing forms of vitality play}

Forms of vitality play is a recently noticed non-figurative play frame linked to early social play and temporal arts in which child and adult - in an active and enjoyable reciprocity context - play together with forms of vitality: the dyad elaborates the dynamics of their own movements and sounds in a repetition-variation form which become the focus and the essence of this play (Español, Martínez, Bordoni, Camarasa, \& Carretero, 2014). The introduction of forms of vitality play requires a brief description of vitality forms and early social play.

\footnotetext{
* Corresponding author at: Facultad Latinoamericana de Ciencias Sociales, Área Educación, Ayacucho 555 (C1026AAC) Ciudad Autónoma de Buenos Aires, Argentina. Tel.: +54 115238 9300; fax: +54 1143751373.

E-mail address: silvia.ana.es@gmail.com (S. Español).
} 


\subsubsection{Forms of vitality}

Forms of vitality (Stern, 2010) have been described to represent how we, as humans, deal with dynamic experiences. Forms of vitality can be easily observed and are clearly available to experience. When a force shifts on any kind of movement we are talking about vitality dynamics, which focus on how excitement, interest, and aliveness fluctuate. Vitality dynamics emerge when the experiences of movement, and what Stern calls its daughters - time, force, space and directionality/intentionality come together all at once as a psychological experience. A form of vitality is a Gestalt, a spontaneous integration of the above mentioned elements emerging from a holistic experience. According to Stern our minds grasps dynamics by means of this pentad. Dynamic forms of vitality are the psychological experiences in which the human mind represents or processes the physical qualities of movement (time, space, force, direction). Forms of vitality are modality non-specific, they are usually paired to a specific content although not exclusively. These can be physical or mental movements, actions, a sequence of dance steps, etc. They are not sensations, nor emotions, although they are both possible contents of a vitality form. Forms of vitality can be directly observed in the behaviour of others. They concern the way in which things are done, the "how". Recently, Di Cesare et al. (2013) suggested that besides the goal and the intention of the performing agent, vitality form is a third aspect an observer may capture when seeing an action done by another individual. Vitality forms characterize action styles, and are detected on the basis of movement dynamics, for example the act of touching can be done in different vitality forms: energetic, gentle, etc. Forms of vitality do not inform us about the goal of the action, they provide us information about the subjective state of the agent performing that action. According to Rochat et al. (2013), individuals with autism reveal severe deficits in recognizing vitality forms. The experiences of dynamic forms of vitality are crucial in interpersonal encounters. Stern highlights they are also at the heart of the temporal arts, which provide an excellent example of how vitality forms work on us, they also show them in a purified form offering a context in which they can disentangle from everyday life contingencies. The temporal arts, music and dance in particular, specially explore the dynamic dimension of human experience. Artistic performances produce arousal shifts, from which vitality forms emerge as the experiential units working in those shifts, sometimes accompanied by specific emotions.

\subsubsection{Forms of vitality in early social play}

One of the first joyful activities adults offer their babies is playing with movement and sensations associated to it: they lift them up, cradle and toss them moving their arms and legs around. In these situations of early social play, they also expose patterns of sound for vocal playing by clicking their tongues and lips, pairing these activities with tickles, rocking, and patting. Sounds, facial expressions, and movements are all resources adults use to hold a baby's attention, generating expectation, driving the baby to different levels of arousal, some impossible to be achieved in solitude. Early social play is a frame often organized in the form of repetition-variation: parents repeat movements, sounds, words or short sentences. This repetition is not mechanical or boring but varied in rhythm, intensity, kinetic or melodic contours; parents also modify the duration of pauses between repetitions playing with their baby's expectations (Español, 2014; Papoušek, 1996; Stern, 1971, 1974, 1985).

In early social play Stern (2010) found a ground where forms of vitality become evident. Sometimes early social play is almost purely a play on vitality forms (e.g. sudden almost explosive movements when a mother gives tickles to her child). Adults usually play with forms of vitality to avoid the child's habituation and boredom. "The result is a theme-and-variation format of vitality forms" (Stern, 2010, p.108). The form of repetition-variation helps adults to level, modulate, and play off the baby's arousal as much as themselves'.

In addition, Stern (2010) defends the idea that forms of vitality are a meeting point between early social play and timebased arts: the feelings that run from excitement to quietness, tension to relaxation, characteristic of early social play, are the same feelings that time-based arts such as dance and music express with mastery; and together with early social play they share the same backbone: the repetition-variation form. In early social play adults manipulate forms of vitality through the repetition-variation form, while the baby participates primarily as a receptor.

\subsubsection{Forms of vitality play}

Although Stern (2010) points out that in early social play the adult plays with forms of vitality, he never assigned a separate name for this play. We agree with him. We cannot call these kinds of play forms of vitality play, for the same reason we do not call pretend play to the incorporation on the adult's behalf of any type of fiction in early social play when playing with his baby - for instance simulating a rubber duck biting the child's leg. The infant play modality is defined in terms of what the baby effectively does while interacting. In this sense, early interactive play is not forms of vitality play but early social play.

Finesse in manipulating or elaborating vitality forms is most likely to be acquired along development, and interactive play is certainly a privileged context for a safe rehearsal. We think that at some point in infancy, early social play turns into forms of vitality play when the child actively wields these vitality forms with repetition and variation. In forms of vitality play, child and adult play together with forms of vitality. Forms of vitality play is a pleasant and joyful play frame, where adult and infant elaborate units (or motifs) of movement and/or sound (like moving a spring forward, stretching and shaking it) according to a repetition-variation form. These units are repeated at least twice with variations in the rhythm of sound and movement patterns, in the form, the dynamic or the quality of movement, in melodic contours, sound sonority, dynamics, and timbre. The whole activity unfolds around the varied repetition of sound and movement, making it the core of this activity. 
When an activity can be considered as play it is always the object of reflection (Pellegrini, 2009). According to Garvey (1977), play is enjoyable and fun; it possesses no extrinsic goals or purposes, it is more an enjoyment of means than an effort destined to a particular purpose; it is spontaneous and voluntary; it involves an active and participative player; and bears a systematic relationship with some non-playful analogue behaviour that allows a contrast between play and nonplay. Activities where children and adults actively manipulate together forms of vitality meet all these criteria: for example, opening and closing a spring is a behaviour that may have practical purposes; however, opening and closing it repeatedly, voluntarily and spontaneously by varying the speed and range of motion and sounds that accompany it, is a recreational activity that contrasts with the purposeful activity of opening and closing the same spring (just as pretending to drink from an empty cup contrasts with the non-playful activity of drinking from a cup). So far, all manipulative actions of vitality forms observed are fun and pleasant, an enjoyment of spontaneous and voluntary means. Hence they are a play with vitality forms.

Extending Stern's idea that forms of vitality are a meeting point between early social play and time-based arts, we assume that early social play, time based arts, and forms of vitality play share the same backbone (the repetition-variation form) and the kind of temporal feeling that emerges from doing something with different vitality forms: energetic, gentle, exciting, lethargic, accelerated, from excitement to quietness, from tense to relaxed, and so on. Early social play can be thought to be the cradle of forms of vitality play, while temporal arts its sophisticated version.

The way of interacting with babies has cultural variations (Lieven \& Stoll, 2013). Through early social play parents transmit "ways of making" and communicating proper to their own culture (Papoušek \& Papoušek, 2002) as well as expressive ways proper to the arts of their culture (Español \& Shifres, 2015; Shifres, 2014). Practices and activities of a cultural community are the socio-cultural context for adult socialization of children's forms and styles of social play in general (Howes, 2011). In a broader sense, Rogoff (2003) suggests that by participating in a cultural community children develop a similar social interaction form and style through joint participation with adults in common activities. These activities are guided by adult practices also common to the cultural community. Forms of vitality play shows the appropriation process on the children's behalf, of the ways in which adults of their own culture handle forms of vitality. This play is therefore culturally grounded.

\subsection{The display modes of forms of vitality play}

The spring example mentioned above is not accidental. The first time we observed a form of vitality play was in a dyad composed of an adult (a researcher) and a 1 year, 10 months old child (Español, 2005, 2007); the game consisted in both participants moving a spring forward, stretching and shaking it in unison. Each one of these movements was associated with a level of intensity (soft/strong) and speed (fast/slow). Play was organized in the form of repetition-variation. When the adult incorporated sounds like 'shhhhh' while slowly bringing the spring towards her, the child responded by slowing the movement down even further; if shaking the spring was an exciting movement already, when the adult incorporated a sound like 'tacataca', the child bursted with laughter. Both, child and adult, made slow and soft, fast and explosive movements in unison, incorporating a diversity of vitality forms. This is the earliest manifestation of a form of vitality play that we have seen. Later on, while running a longitudinal case study on play during the third year of life (Español, Bordoni, Martínez, Camarasa, \& Carretero, 2010), we noticed the frequent appearance of similar play situations throughout the sessions. We were also able to observe that there are different display modes of forms of vitality play such as simple or pure, and combined with symbolic play patterns.

\subsubsection{Remarks on symbolic play}

Symbolic play begins at the pre-symbolic or presentational level - known as functional play - when children begin to use objects out of their context (e.g. use an empty spoon for "eating”) (Bates, Benigni, Bretherton, Camaioni, \& Volterra, 1979; Español, 2004; Garvey, 1977; Hobson, 1993; McCune \& Agayoff, 2002; Rivière, 2002, 2003a). With the irruption of substitutions, their combination and sequencing, pretend play emerges. Pretend play proceeds from simple, isolated substitutions (using a toy rake as a spoon) to multiple ones (feeding a toy horse from a plastic egg box) (Español, 2004; Garvey, 1977) Role assumption articulated with language acquisition (playing teacher, mother, etc.) marks the appearance of role play (Elkonin, 1980). Functional play is generally recognized as emerging towards the end of the first year of life. Later, at around the eighteenth month, when the first substitutions arise in different action scenarios, we are at the core of pretend play. Finally, role play appears clearly around the third year when children can easily assume social roles. In all these recognized kinds of symbolic play the focus is always set on figurative or representational content; there's always "something" being represented or figured. Although the child can play symbolically in solitude (as described by Piaget in 1962), the emergence and development of play is linked to social interaction and intersubjectivity skills (Göncü, 1993; Göncü \& Gaskings, 2011; Vygotsky, 1967), and it is also culturally grounded (Kavanaugh, 2011).

\subsubsection{Systematic study of display modes of forms of vitality play}

After making sporadic observations on forms of vitality play, we decided to start a systematic study of it using the material collected in our longitudinal case study on play. We observed the existence of different display modes of forms of vitality play during the third year of life. By applying the constant comparative method that allows the detection of the phenomenon's specific properties and the generation of open revisable categories (Glaser \& Strauss, 1967) we generated one general category and four subcategories of display modes of forms of vitality play (Español et al., 2014). The general category is the one we used previously to describe forms of vitality play (from now on FoVP). This general category may appear in 
four display modes. Improvised FoVP in which units of movement and/or sound (motifs) are repeated with spontaneous and improvised variations. Ritualized FoVP where movements and/or melodic contours are organized around cultural established songs or dance. In both, the whole activity unfolds around the varied repetition of sounds and movements, making it the unique focus and the essence of this play in detriment of any figurative content. FoVP combined with pretend play where substitution occurs together with repeated-varied motifs of movement and/or sound. The activity evolves around the varied repetition of sounds and movements, making it the core of this play mixed with fictional actions. FoVP combined with role play where a simulation of a social role occurs together with repeated units of movement and/or sound (motifs). The activity evolves around the varied repetition of sounds and movements, making it the core of this play mixed with fictional characters or playing a role. No cases of FoVP combined with functional play were found.

Among the simple appearing forms of FoVP, improvised FoVP is extremely interesting because it exhibits the spontaneous, graceful, and easy adult-child ability to co-create playful activities. Joint improvisation is the hallmark of this play in which improvisations occur on-line without resorting to any figurative content. They are an original, recreational activity emerging spontaneously. They can be brief or long, may involve a similar or dissimilar level of participation in the making together, they can be organized in a very simple or extremely complex fashion. For example, one girl, at 2 years, 3 months, slowly and sinuously lets her back roll down a couch towards the floor, and then quickly straightens herself back up. She repeats this sequence three times, varying the form and duration of her movements and the vocalizations that accompany every repetition. The adult involved performs similar movements and melodic contours. More complex play is also frequent, like a 2 year, 4 months old girl and an adult, taking turns to draw some stripes while vocalizing invented words for approximately 2 min. The microanalytical study of this sequence's vocalizations (Bordoni \& Martínez, 2011) revealed that girl and adult not only shared the time pattern of their performances, but towards the play's end they got to organize them musically in a shared metric hierarchy. The microanalysis of a fragment of this play permitted the observation of alternating movement shifts organized by the adult's movement-stillness pattern and the girl's fore-aft, who only towards the play's end managed to introduce some tranquillity in her behaviour (Bordoni \& Español, 2011). This play mode tends to become highly organized with execution and then disappears. It usually does not recur. Maybe the same improvised and fleeting character is what, despite its richness and complexity, prevented its observation and description (at least to our knowledge). Ritualized FoVP also arises spontaneously although it is constituted from pre-established organized forms of sound and movement. This highly ritualized type of play includes children's songs, advertising runs, showcased choreographies, and all kind of events in which one could recognize song and dance modes belonging to the dance and music repertoire of the child's culture. For example, at 2 years and 1 month, a girl takes a pile of rectangles that are held together by a ribbon and sings 'un tallarín, un tallarín' (a spaghetti, a spaghetti) flapping the arms. When she finishes singing this phrase she looks at the adult who asks smiling: ‘uun tallarín?' (A spaghetti?). The girl goes back to singing 'un tallarín, un tallarín' (a spaghetti, a spaghetti), while rotating her arms and torso to the sides. And continues singing 'que se mueve por acá' (moving over here), moving the toy with shorter movements in front of her visual field, accompanying the vocalization rallentando 'por acá' (over here), ending with a sudden lowering movement that hits the object on the table. The struck object's noise is synchronic with her last vocalization. The adult asks her '¿un tallarín?' (a spaghetti?), supposing the girl is representing the spaghetti with the pile of rectangles. The girl does not answer: she's not pretend-playing but busy playing with her own sounds and movements, trying to make the dynamics and intensity match her sounds and jointly vary on a pre-established performance plan that exercises a children song belonging to the popular music repertoire of the girl's cultural context.

In combined patterns of play the varied repetition of movements and sounds blends with figurative and symbolic contents beautifying and enriching fiction. In FoVP combined with pretend play the sound and movement organization enhance symbolic substitution. For example, a 2 years and 1 month old girl grabs and moves a spring like a steering wheel saying 'el paseo de papá' (daddy's ride). When the hand hits the spring twice she says 'toco bocina pip pip' (I play the horn pip pip); repeating 'pip pip' and hitting it again. She begins to rotate it with sinuous arms and trunk movements singing 'el paseo de papá' (daddy's ride, daddy's ride); then she tiptoes quickly and repeats 'el paseo de papá, el paseo de papá' (daddy's ride, daddy's ride). The spring symbolically replaces the wheel and the sinuous movements of arms and trunk seem to evoke the path of a car driving on the street. The repetition-variation of sounds and movements made by the child embellishes her pretend playing. In FoVP combined with role play the repetition of movements and sounds and its expressive features combine with the assumption of a specific social role. For example, a 2 year, 9 months old girl while playing dolls starts singing with a nasal, strained voice 'somos las robóticas' (we are the robotics) repeating this eight times in a variety of ways, dancing, moving the dolls and looking at them, making them dance. Then, she takes a new set of dolls adding 'ustedes son las brujas' (you are the witches) strongly hitting them twice against a table saying the two witches represent the adults in the room, while she and her sister are the robots. The sequence lasts about a minute and a half, varied repetitions of various sound motifs or units occur ('somos las robóticas' [we are the robotics], 'las brujas no existen más' [the witches don't exist anymore]) and also kinetic (movements that accompany these verses). All sung phrases are on-line created by the girl, and her expressive features (sound and movement) typify the characters (witches and robots). For more detail of these and other examples of the four display modes, see Español et al. (2014).

\subsection{Dialogical approach and second person methodology for the study of forms of vitality play}

Forms of vitality play is, in essence, an interactive phenomenon whose comprehension emerges when adopting a dialogical approach. This theoretical perspective describes dialogue as mutually co-regulated movements that emerge when two (or 
more) bodies encounter one another. In this sense, dialogue is a multi-faceted process that looks well beyond typical notions of conversation, parlance, and exchange. Co-regulation appears to be related to the personal experience of resonance or being with the other, and partners are open to mutual influence. The multi-faceted process of dialogue is organized in frames that dynamically emerge, get settled, and change. Frames are coherent themed co-action pieces involving mutual co-oriented forms between participants (Fogel \& Garvey, 2007; Garvey \& Fogel, 2007). In the building together of dialogical forms a mutual knowledge is achieved that serves as a background for the dyad to negotiate new elements that can be seen as emerging figures bringing novelty to what has been established (Lyra, 2007). Each forms of vitality play instance is a culturally grounded frame in which the dyad builds together a dialogical form of elaborated sounds and movements.

Forms of vitality play emerges when interpersonal interaction flows and social engagement arises. Reddy (2008) proposes a second person methodology for the psychological research of intersubjective phenomena (as opposed to the distanced and objective third person studies, and the subjective studies in first person). She suggests that the knowledge we can generate on the phenomena of interpersonal involvement essentially depends on the intersubjective relationship established, i.e., the person-to-person genuine encounter. In our studies of play, we follow Reddy's psychology of intersubjective phenomena's methodology proposal (Español, 2005; Español et al., 2010; Español et al., 2014). In all of them we studied the researcherchild dyad (a particular case of the classic adult-child dyad). The researcher was particularly attentive to promote situations of play involving sound and movement as well as figurative play. The characteristic aspect of this procedure is the active participation of the researcher, generating a special kind of interaction - different from every-day interactions. The researcher can register her own experiences and reactions on-line, generating changes around them, and thanks to the availability of registered audiovisual resources she can remotely observe them, retrieving her own previous experience (for more details on the procedure see Español et al., 2014).

In our longitudinal case study (Español et al., 2010), where the convergence technique (Bell, 1953) or accelerated longitudinal designs (Duncan \& Duncan, 2012) were applied, we recorded interaction sessions of two child-research dyads during the child's third year. Each symbolic play event - functional, pretend and role play - was coded. With the same recorded material, in Español et al. (2014), we generated the category of forms of vitality play and its four display modes already referred. This research shows that children in their dialogical exchanges develop the ability to actively execute and manipulate, namely, to play with forms of vitality in four display modes. Still to be studied is the frequency of forms of vitality, and whether its frequency changes with age during the third year of life. In this article, with the use of the same recorded material, we investigated the developmental changes occurring in simple forms of vitality play's rate, in the three display modes of symbolic play's rate, and in the two display modes of combined patterns' rate, during the third year of life.

\section{Method}

\subsection{Participants}

Videotaped interactions of 2 adult-child dyads from an existing longitudinal dataset (Español et al., 2010, and Español et al., 2014) were used. In both dyads, the adult was the main researcher in this study (first author of this paper). As previously mentioned, this choice echoes the methodology used by Reddy (2008) for studying the psychology of intersubjective phenomena (see Español et al., 2014, for a complete rationale for the dyad's choice). The tapes were recorded during home visits that took place when the two girls were transiting their third year of life. The first girl was 2 years in the first session and 2 years, 5 months in the last one. The second child was 2 years, 4 months in the first session and 2 years, 10 months in the last one. The first girl is the only child of a middle-class Argentinean family. The other girl is the third child to middle-class Argentinean parents. None of them were born prematurely nor have been diagnosed with any developmental disorders. Both girl's and adult's native language is Spanish.

\subsection{Procedure}

\subsubsection{Videotaping}

The interactive sessions were recorded in naturalistic contexts in the girls' homes. A total of $17 \mathrm{~h}, 48 \mathrm{~min}$ were filmed in 28 sessions. The researcher visited the girls every 15 days for approximately $45 \mathrm{~min}$. A set of appropriate objects for play activities was displayed in front of the girls: objects of conventional use, dolls that could easily have roles assigned to them, and objects of non-conventional use. The researcher was particularly attentive to promote situations of play involving sound and movement as well as figurative play. The characteristic aspect of this procedure is the active participation of the researcher, generating a special kind of interaction - different from every-day interactions.

\subsubsection{Coding symbolic play and forms of vitality play}

Based on symbolic play categories used in Español et al. (2010) and in forms of vitality play categories generated in Español et al. (2014) we built an observational code to identify events of forms of vitality play and symbolic play. The observational code is formed by 8 basic categories: functional play, pretend play, role play, improvised FoVP, ritualized FoVP, FoVP combined with functional play, FoVP combined with pretend play, and FoVP combined with role play. 
1. Functional Play: every ludic activity presenting at least one case of decontextualized use of an object.

2. Pretend Play: every ludic activity where at least one substitution is present.

3. Role Play: every ludic activity that implies the simulation of a social role.

4. Improvised FoVP: is an improvised frame in which units of movement and/or sound (motifs) are repeated varying: (a) rhythmic patterns, melodic contours, dynamics, sonority and timbre of sound, and/or (b) rhythmic patterns, form, dynamics, and quality of movement. The whole activity unfolds around the varied repetition of sounds and movements, making it the unique focus and the essence of this play in detriment of any figurative or symbolic content.

5. Ritualized FoVP: is a frame where rhythmic patterns, forms and dynamics of recurring movements and/or melodic contours are organized around cultural established songs or dance. The whole activity unfolds around the varied repetition of sounds and movements, making it the unique focus and the essence of this play in detriment of any figurative content.

6. FoVP Combined with Functional Play: any ludic activity where combined categories of functional play with improvised and ritualized FoVP categories are present in any proportion.

7. FoVP Combined with Pretend Play: any ludic activity where combined categories of pretend play with improvised and ritualized FoVP categories are present in any proportion

8. FOVP Combined with Role Play: any ludic activity where combined categories of role play with improvised and ritualized FoVP categories are present in any proportion.

All 8 basic categories were grouped in 3 superordinate categories: Symbolic play (includes 1, 2 and 3), Simple FoVP ( 4 and 5), and Combined patterns of play (6, 7, and 8).

The observational code was applied to every recorded session, and the events of play were counted and identified. The expression event of play was applied to any given behaviour over $1 \mathrm{~s} \mathrm{long}{ }^{1}$ performed by the girls, corresponding to the description of the different play categories.

\subsubsection{Coding reliability}

Coding involved two couples of independent coders (the first four authors of this paper) followed by a discussion regarding items of disagreement. The following steps were employed: (a) each recorded session was thoroughly watched by two independent coders; (b) those play events subject to disagreement between coders were discussed by the whole group until consensus was reached; (c) in the few occasions where a consensus was not reached, the event was dismissed. This procedure is consistent with that used in social interaction studies (i.e. Forster \& Iacono, 2013; Jonsson et al., 2001).

\subsubsection{Analyses}

Based on the code's application, a total of 391 events were identified across $17 \mathrm{~h}, 48 \mathrm{~min}$ of recorded material. The rate of every type of play was calculated for different age periods. The data was clustered by trimesters. Of the 28 filmed sessions, 5 correspond to the first quarter of the third year, with a total duration of $4 \mathrm{~h}, 33 \mathrm{~min}$. In the second quarter 10 sessions were recorded with a total duration of $6 \mathrm{~h}, 30 \mathrm{~min}$. In the third one, another 10 sessions were recorded with a total duration of $5 \mathrm{~h}, 10 \mathrm{~min}$, and in the last quarter we recorded 3 sessions with a total duration of $1 \mathrm{~h}, 35 \mathrm{~min}$. To measure the frequency of play events, we calculated the apparition rate of each play category: $\sum$ play events/filmed hours, by trimester.

\section{Results}

Rates trajectories of symbolic play, forms of vitality play, and combined patterns of play during the third year of life are described. The analysis first examines developmental changes in the rate of the 3 superordinate categories: forms of vitality play, symbolic play, and combined patterns of play, during the third year of life. Secondly it examines developmental changes in the rate of the 8 basic categories: improvised FoVP, ritualized FoVP, functional play, pretend play, role play, FoVP combined with functional play, FoVP combined with pretend play, and FoVP combined with role play.

The 3 superordinate categories are present from the beginning of the studied period. Table 1 shows that symbolic play holds the highest rate during the third year of life, in comparison to FoVP and combined patterns of play. Symbolic play rates decrease from 11 events per hour in the first quarter of the third year to 6 events an hour in the second quarter. In the third and fourth quarters, events of symbolic play notoriously increase (in the latter they reach 21.84 events per hour). FoVP is present from the beginning and throughout the third year of life at an approximate constant rate of 8 events per hour. In the first quarter of the third year, this rate value is slightly lower to that of symbolic play, while in the second quarter, FoVP's rate outgrows that of symbolic play. Later, in the third quarter, the relationship shifts back to the one in the first quarter; and finally, the rate of symbolic play is twice and a half FoVP's rate. Combined patterns of play show lower rates than the other categories, inferior to 6 play events per hour. Combined patterns of play show a trajectory of ' $U$ ' turn during the studied period with the lowest rate; in the first quarter, more than 4 combined play events were recorded in an hour, in the second

\footnotetext{
1 This duration criteria was used to include some fleeting events of functional and/or pretend play; for example, when the girls revolved with a spoon inside an empty cup and went on to another activity or when they pretended a rolled place mat to be a lit candle to which they blew, or they said "Look it's a flower", showing the same threaded placemat. These examples lasted little more than $1 \mathrm{~s}$. The FoVP exceeded this duration and generally lasted over $10 \mathrm{~s}$.
} 
Table 1

Rate of each type of play's superordinate categories by age period. Third year of life.

\begin{tabular}{llll}
\hline & Forms of vitality play & Symbolic play & Combined patterns of play \\
\hline 1st quarter & $8.16^{\mathrm{a}}$ & $11.03^{\mathrm{b}}$ & $5.83^{\mathrm{b}}$ \\
2nd quarter & $8.29^{\mathrm{a}}$ & $12.31^{\mathrm{b}}$ & $2.31^{\mathrm{c}}$ \\
3rd quarter & $7.88^{\mathrm{a}}$ & $20.84^{\mathrm{b}}$ & $2.88^{\mathrm{c}}$ \\
4th quarter & $8.21^{\mathrm{a}}$ & $5.68^{\mathrm{c}}$ \\
\hline
\end{tabular}

a Events of forms of vitality play per hour.

b Events of symbolic play per hour.

c Events of combined patterns of play per hour.

Table 2

Rate of each type of play's basic categories by age period. Third year of life.

\begin{tabular}{|c|c|c|c|c|c|c|c|c|}
\hline & I-FoVP & R-FoVP & FunP & PreP & RoP & FunP\&FoVP & PreP\&FoVP & RoP\&FoVP \\
\hline 1st quarter & $6.40^{\mathrm{a}}$ & $1.76^{\mathrm{b}}$ & $1.98^{c}$ & $9.04^{\mathrm{d}}$ & $0^{e}$ & $0^{f}$ & $4.4^{g}$ & $0^{\mathrm{h}}$ \\
\hline 2nd quarter & $6.45^{\mathrm{a}}$ & $1.84^{\mathrm{b}}$ & $0.31^{c}$ & $4.91^{\mathrm{d}}$ & $0.61^{\mathrm{e}}$ & $0^{f}$ & $2.3^{g}$ & $0^{\mathrm{h}}$ \\
\hline 3rd quarter & $5.00^{\mathrm{a}}$ & $2.88^{\mathrm{b}}$ & $0.58^{c}$ & $11.15^{\mathrm{d}}$ & $0.58^{e}$ & $0^{f}$ & $2.5^{g}$ & $0.38^{\mathrm{h}}$ \\
\hline 4th quarter & $5.68^{\mathrm{a}}$ & $2.53^{\mathrm{b}}$ & $0.00^{c}$ & $18.32^{\mathrm{d}}$ & $2.53^{\mathrm{e}}$ & $0^{f}$ & $3.7^{\mathrm{g}}$ & $1.89^{\mathrm{h}}$ \\
\hline
\end{tabular}

Notes. I-FoVP=improvised forms of vitality play; R-FoVP= ritualized forms of vitality play, FunP=functional play, PreP= pretend play; RoP= role play; FunP\&FoVP = functional play combined with forms of vitality play; PreP\&FoVP= pretend play combined with forms of vitality play; RoP\&FoVP= role play combined with forms of vitality play.

a Events of I-FoVP per hour.

b Events of R-FoVP per hour.

c Events of FunP per hour.

d Events of PreP per hour.

e Events of RoP per hour.

f Events of FunP\&FoVP per hour.

$g$ Events of PreP\&FoVP per hour.

h Events of RoP\&FoVP per hour.

and third quarters, somewhat more than 2 play events an hour, and by the end of the studied period, the rate ascends once again to almost 6 combined play events an hour.

As shown in Table 2 the rate of the basic categories display different developmental trajectories. During the whole third year of life, improvised FoVP's rate is higher than ritualized FoVP's (between 6 improvised FoVP events per hour versus close to 2 ritualized FoVP events per hour). Likewise, their evolution during the third year is inverted: while improvised FoVP decreases during the second half of the third year, ritualized FoVP's increases. These subtle changes in proportion are compensated in a way that the superordinate category's rate remains stable throughout the studied period. Pretend play achieves the highest rate and follows the same evolving curve as the superordinate category, from 9 play events an hour, descending to half during the second quarter, and ascending during the second half of the studied period (from 11 to 18 pretend play events per hour). Functional play's rate tends to decrease along the third year, starting at 2 play events an hour to its full extinction in the last quarter. Role play's doesn't emerge until the second quarter and increases towards the fourth quarter. There were no cases of FoVP combined with functional play. FoVP combined with pretend play is present from the beginning evolving into a U turn; in the first quarters, the combined play rate is nearly half of simple pretend play's, in the last two quarters simple play is much more frequent than the combined form (between 11 and 18 pretend play events per hour vs. between 2.5 and 3.8 of FoVP combined with pretend play). FoVP combined with role play is absent until the third quarter, increasing during the last quarter.

\section{Discussion}

Despite the recognized relevance of play in infant development and the extent to which it has been studied, our work shows that something novel can be said about children play. In Español et al. (2014) we described an unnoticed kind of farreaching non-figurative play frame in infancy: forms of vitality play. The present article focused on the study of the FoVP's rate and its developmental change during the third year of life in a longitudinal study case with a particular interactive dyad (researcher-infant). We decided to do a rate study because the frequency of an activity tells us what a child is dealing with; it gives us a clue of the value of that activity at that particular time in development. This especially applies to play, given that, while contributing to master situations, play reflects on this and depends on this mastery for developing (Rivière, 2003b). Therefore, in the first place we measured simple FoVP's rate during the third year of life. To weigh the relevance of simple FoVP's rate we also measured the rate of symbolic play (traditionally the most studied in developmental psychology); and given that sometimes FoVP appears combined with symbolic play, we also measured the rate of this combination. Secondly, we observed the superordinary categories rates' trajectories, the play's basic categories rates trajectories during the third year of life. Due to the characteristics of the researching device -with the active participation of the "well informed researcher" in social interaction with the girls-, the data collected show the trajectories of the frequency of these types of play in a gleaned context that encourages both kinds of play. We have analyzed changes in the rate of every type of play by trimester, now the 
discussion is organized around the rate trajectory of each superordinate category followed by the rate change of the basic categories, and the relationships between them.

\subsection{Simple forms of vitality play}

During the third year, simple FoVP is present at a constant rate (around 8 simple FoVP events per hour). Its rate value does not fall far from that of symbolic play during the first three quarters, but it is duplicated by the symbolic play's rate in the last quarter (the moment in which symbolic play is the most frequent form of play). In simple FoVP the whole activity unfolds around the varied repetition of sounds and movements, which becomes the play's focus and essence in detriment of any figurative content. The detection of simple FoVP events shows the independence of this type of play. Its rate reveals that elaborated activities developing independently from any figurative or symbolic content are not sporadic or unusual, nor tend towards disappearing during the studied period. On the contrary, the elaboration of movements and sounds in a repetition-variation structure, in detriment of any figurative content, is an activity occupying a good proportion of infant play and remains constant during the third year of life. Its constant rate throughout the third year induces us to think of it as a backdrop companion to development. As Stern pointed out, the baby perceives vitality forms very early in life and participates in early dyadic social play with these dynamic forms. Our research shows that children go beyond this early social play and develop the ability to actively execute and manipulate forms of vitality. In context of social frames, infants go from participating to purposefully play with forms of vitality. In the studied period, vitality forms are shown as an extra resource for recreational activity in social interaction. Since the ability to recognize forms of vitality in the other's behaviour and to engage with them is essential in the field of interpersonal experience, FoVP can be seen as a playful activity that favours the recognition of different forms of vitality in a context in which, without taking any risks, multiple interactive matching of sound and motor gestures is exercised. At its heart, the child can experience her own agency or authorship in the vicissitudes of interpersonal encounters, actively entering experiences of mutuality, intimacy and intersubjectivity that characterize the human world.

\subsubsection{Improvised and ritualized forms of vitality play}

FoVP is manifested in two simple display modes (improvised FoVP and ritualized FoVP) which rates follow different trajectories during the studied period. Even if improvised FoVP's rate is higher than that of ritualized FoVP, they evolve inversely during the third year: while improvised FoVP decreases in the second half, ritualized FoVP increases. These subtle changes in proportion are compensated in such a way that the superordinate category's rate remains stable throughout the studied period. It is possible that the rate's trajectory may be indicating the growing relevance of the child's appropriation of decanted products of culture. Improvised FoVP's are fleeting, rarely established or repeated forms of play. In general they reach a substantial form and disappear once they are executed. If they do remain from session to session, the joy of recognition runs along with them but in the end they disappear. The high rate of improvised FoVP suggests how relevant unplanned, spontaneous, ongoing performances of sound and movement are in the co-construction of the researcher and child interaction. Conventional forms of singing and dancing are "culture packages" for child development. When ritualized and cultural established songs and movements are introduced, there is an evident tendency in the exchanges to continuingly construct shared meaning and public cultural activities of meaning making. In this sense, we can think of ritualized FoVP as a road towards establishing cultural shared activities. The social value of these decanted products of culture undoubtedly favours their execution and conservation in the child's repertoire.

Stern defended the idea that forms of vitality are a meeting point between early social play and time-based arts; he particularly noticed that early social play and temporal arts share the same backbone: the repetition-variation form. Improvised FoVP and ritualized FoVP are organized in this fashion. This is one of the reasons why we assume these play events can be seen as an intermediate link between early social play and the temporal arts. Thus, both ritualized and improvised FoVP might be preparing the child for participation in the temporal arts.

\subsection{Symbolic play}

Symbolic play's rates that were registered in our study confirm that, as repeatedly pointed out in relevant literature, the third year of life is a flourishing period for symbolic play. Functional play shows a low rate throughout the third year and a tendency to decrease. It might finally end up subsumed to the other two kinds of symbolic play (pretend and role play). Pretend play is present from the beginning of the third year; it blossoms in the second half and tends to increase towards the end where it reaches the highest rate, following the same evolving curve as the superordinate category (symbolic play). Role play is a novelty in the studied period. It appears in the second quarter in its simple form. Although symbolic play can appear alone, our researching device (the constant, watchful and interactively willing presence of the researcher) made no cases of solitary symbolic play.

\subsection{Combined forms of FoVP and symbolic play}

FoVP gets mixed with playful infant symbolic activities generating combined forms of play. The absence of FoVP combined with functional play events probably relates to the natural decay of functional play during this developmental period. While 
pretend play's rate duplicates during the third year, the rate of FoVP combined with pretend play remains relatively steady, always bellow the simple form's rate. The relationship between both rates leads us to think that when playing pretence, the child uses FoVP as a resource to elaborate symbolic events, and that once he masters the ability to play pretence, he tends to execute it more frequently without the accompaniment of FoVP.

The studied period allowed us to witness the particular temporal relation between a simple form of play and a combined one. Role play appears in the second quarter in its simple form. The combined form role play-FoVP appears later, in the third quarter of the third year with a tendency to increase towards the fourth quarter. This means that play develops by means of a combination between previously established types of play (FoVP) and novel ones (role play). In prior phenomena essential to development, evolution by means of a combination of different skills has been observed. For example, a combination between previously established, directed to objects schemas, and directed to people schemas, permits joint attention and other triadic experiences to appear at around 9 months (Sugarman, 1984). The temporal relation between a simple form of play and a combined one might be reflecting the same phenomena: FoVP (present beginning the third year of life at a constant rate) seems to be there available for the child to be combined with new ways of symbolic play - in this case, role play - that develop in time once this new way of symbolic play has been established. Possibly this "simple-combined" sequence will also manifest in relation to pretend play, but since it is present from the beginning of the studied period, we could not observe whether it first appeared in its simple or combined form. Anyhow, the existence of combined forms of play present from the beginning to the end of the third year, and our "simple-combined sequence hypothesis" persuades us to think of forms of vitality play is as a good runway for the development of symbolic play.

\subsection{Final comments}

The study of the trajectories of frequencies performed shows that, in a gleaned context encouraging both kinds of play, the girls were able to play FoVP almost as frequently as symbolic play; and often play more the simple version (improvised and ritualized) than the combined with symbolic play form. Much work remains to be done towards generating and strengthening a grounded theory on FoVP. It is important to observe how it emerges and configurates in present social interaction and in real time. To that end, it is necessary to observe them under a temporal magnifying glass, making a frame-by-frame observation. We still need to perform detailed tracking of a qualitative microanalysis in order to offer more specific observations. All registered cases of Forms of vitality play were social interactions with an evident level of social involvement. The researcher's participation varied from active inclusion in the play to the adoption of the role of spectator. We intend in the near future to analyze the different possible ways of accompaniment.

\section{Acknowledgements}

The authors are grateful to Pablo De Grande for his methodological helpful assistance. This research was supported by grants from the National Agency for Science and Technology (ANPCyT, Argentina) (PICT 2013-0368).

\section{References}

Bates, E., Benigni, I., Bretherton, L., Camaioni, L., \& Volterra, V. (1979). Cognition and communication from nine to thirteen months: Correlational findings. In E. Bates (Ed.), The emergence of symbols: Cognition and communication in infancy (pp. 69-140). Nueva York: Academic Press.

Bell, R. Q. (1953). Convergence: An accelerated longitudinal approach. Child Development: 24., (2), $145-152$.

Bordoni, M., \& Español, S. (2011). Moviéndonos juntos: el movimiento en el juego musical imitativo. In A. Pereira Ghiena, P. Jacquier, M. Valles, \& M. Martínez (Eds.), Musicalidad humana: Debates actuales en evolución, desarrollo, cognición e implicancias socioculturales (pp. 83-95). Buenos Aires: SaccomUniversidad Abierta Interamericana.

Bordoni, M., \& Martínez, I. (2011). Imitación mutua y juego musical en la infancia [Mutual imitation and musical play in infancy]. Psicología del desarrollo: 1., (2), 69-78.

Di Cesare, G., Di Dio, C., Rochat, M. J., Sinigaglia, C., Bruschweiler-Stern, N., Stern, D. N., et al. (2013). The neural correlates of ‘vitality form’ recognition: An fMRI study. Social Cognitive E Affective Neuroscience: 51., (10), 1918-1924.

Duncan, S., \& Duncan, T. (2012). Accelerated longitudinal designs. In B. Laursen, T. Little, \& N. Card (Eds.), Handbook of developmental research methods (pp. 31-45). New York: Guilford Press.

Elkonin, D. (1980). (The psychology of play) Psicología del juego. Visor: Madrid (V Uribes Trans.).

Español, S. (2004). (How to do things without words. Gesture and fiction in early infancy) Cómo hacer cosas sin palabras: gesto y ficción en la infancia temprana. Madrid, España: Antonio Machado.

Español, S. (2005). Ontogénesis de la experiencia estética La actitud contemplativa y las artes temporales en la infancia [Ontogenesis of aesthetic experience: Contemplative attitude and the temporal arts in infancy]. Estudios de Psicología: 26., (2), 139-172.

Español, S. (2007). Time and movement in symbol formation. In J. Valsiner, \& A. Rosa (Eds.), The Cambridge handbook of socio-cultural psychology (pp. 238-255). New York, NY: Cambridge University Press. Español (2005).

Español, S. (2014). La forma repetición variación Una estrategia para la reciprocidad. In E. S. Español (Ed.), Psicología de la música y psicología del desarrollo Una exploración interdisciplinaria sobre la musicalidad humana (pp. 157-192). Buenos Aires: Paidós.

Español, S., \& Shifres, F. (2015). The artistic infant directed performance: A mycroanalysis of the adult's movements and sounds. Integrative Psychological and Behavioral Science, http://dx.doi.org/10.1007/s12124-015-9308-4

Español, S., Bordoni, M., Martínez, M., Camarasa, R., \& Carretero, S. (2010). Un estudio multidisciplinario sobre el juego en la infancia temprana. In Paper presented at I Congreso Internacional de Psicología: Universidad Nacional de Rosario, Rosario, Argentina.

Español, S., Martínez, M., Bordoni, M., Camarasa, R., \& Carretero, S. (2014). Forms of vitality play in infancy. Integrative Psychological and Behavioral Science: 48., (4), 479-502.

Fogel, A., \& Garvey, A. (2007). Alive communication. Infant Behavior E Development: 30., 251-257.

Forster, S., \& Iacono, T. (2013). The nature of affect attunement used by disability support workers interacting with adults with profound intellectual and multiple disabilities. Journal of Intellectual Disability Research: 58., (12), 1105-1120. 
Garvey, A., \& Fogel, A. (2007). Dialogical change processes, emotions, and the early emergence of self. International Journal for Dialogical Science: 2., (1), $51-76$.

Garvey, C. (1977). Play. London: Open Books Publishing.

Glaser, B. G., \& Strauss, A. L. (1967). The discovery of grounded theory. Chicago: Aldine Publishing Company.

Göncü, A., \& Gaskings, S. (2011). Comparing and extending Piaget‘s and Vygotsky‘s understandings of Play: Symbolic play as individual, sociocultural, and educational interpretation. In A. Pellegrini (Ed.), The Oxford Handbook of the development of play (pp. 48-57). New York: Oxford University Press.

Göncü, A. (1993). Development of intersubjetivite in social pretend play. Human Development: 36., $185-198$.

Hobson, R. P. (1993). Autism and the development of mind. Hove, UK: Erlbaum.

Howes, C. (2011). Social Play of children with adults and peers. In A. Pellegrini (Ed.), The Oxford Handbook of the development of play (pp. 231-244). New York: Oxford University Press.

Jonsson, C. O., Clinton, D., Fahrman, M., Mazzaglia, G., Novak, S., \& Sörhus, K. (2001). How do mothers signal shared feeling-states to their infants? An investigation of affect attunement and imitation during the first year of life. Scandinavian Journal of Psychology: 42., (4), 377-381.

Kavanaugh, R. (2011). Origins and consequences of social preten play. In A. Pellegrini (Ed.), The Oxford Handbook of the development of play (pp. 296-307). New York: Oxford University Press.

Lieven, E., \& Stoll, S. (2013). Early communicative development in two cultures: A comparison of the communicative environments of children from two cultures. Human Development: 56., 178-206.

Lyra, M. C. D. P. (2007). On abbreviation: Dialogue in early life. International Journal for Dialogical Science: 2., (1), 15-44.

McCune, L., \& Agayoff, J. (2002). Pretending as representation: A developmental and comparative review. In R. W. Mitchell (Ed.), Pretending and imagination in animals and children (pp. 43-55). Cambridge: Cambridge University Press.

Papoušek, M. (1996). Intuitive parenting: A hidden source of musical stimulation in infancy. In I Deliège, \& J. Sloboda (Eds.), Musical beginnings. Origins and development of musical competence (pp. 88-112). Oxford: Oxford University Press.

Papoušek, M., \& Papoušek, H. (2002). Intuitive parenting. In M. H. Bornstein (Ed.), Handbook of parenting Volumen 2. Biology and ecology of parenting (pp. 183-203). Mahwah: Lawrence Erlbaum.

Pellegrini, A. D. (2009). The role of play in human development. Oxford University Press.

Piaget, J. (1962). Play, dreams and imitation in childhood. New York, NY: Norton (C. Gattegno \& F.M. Hodgson Trans.).

Reddy, V. (2008). How infants know minds. Cambridge: Harvard University Press.

Rivière, Á. (2002). (Autistic spectrum inventory) Inventario de espectro autista. Buenos Aires: Fundec.

Rivière, Á. (2003a). Acción e interacción en el origen del símbolo. In M. Belinchón, A. Rosa, M. Sotillo, I. Marichalar, \& R. Ángel (Series Eds.) \&, Obras Escogidas : Vol. II. (Vol. II) (pp. 77-108). Madrid: Medica Panamericana.

Rivière, Á. (2003b). El juego simbólico en niños ciegos. In E. M. Belinchón, A. Rosas, M. Sotillo, \& I. Marichalar (Eds.), Ángel Rivière. Obras escogidas. Volumen II. Lenguaje, simbolización y alteraciones del desarollo (pp. 173-192). Madrid: Médica Panamericana.

Rochat, M. J., Veroni, V., Bruschweiler-Stern, N., Pieraccini, C., Bonnet-Brilhault, F., Barthélémy, C., et al. (2013). Impaired vitality form recognition in autism. Neuropsychologia: 51., (10), 1918-1924.

Rogoff, B. (2003). The cultural nature of human development. Oxford University Press.

Shifres, F. (2014). Algo más sobre el enlace entre la infancia temprana y la música: el poder explicativo del rubato. In E. S. Español (comp.) (Ed.), Psicología de la música y psicología del desarrollo. Una exploración interdisciplinaria sobre la musicalidad humana (pp. 121-170). Buenos Aires: Paidós.

Stern, D. (1971). A microanalysis of mother-infant interaction. Journal of the American Academy of Child Psychiatry: $10 ., 501-517$.

Stern, D. (1974). Mother and infant at play: The dyadic interaction involving facial, vocal, and gaze behaviors. In M. Lewis, \& L. Rosenblum (Eds.), The effect of the infant on its caregiver. New York: Wiley.

Stern, D. (1985). The interpersonal world of the infant. A view from psychoanalysis and developmental psychology. New York, NY: Basic Books.

Stern, D. (2010). Forms of vitality. Exploring dynamic experience in psychology, the arts, psychotherapy and development. New York, NY: Oxford University Press.

Sugarman, S. (1984). The development of preverbal communication: its contribution and limits in promoting the development of language. In R. Schiefelbusch, \& Pickar (Eds.), The acquisition of communicative competence. Baltimore: University Park Press.

Vygotsky, L. S. (1967). Play and its role in the mental development of the child. Soviet Psychology: 5., (3), 6-18. 